\title{
Designing an Optimal Shape Warehouse
}

\author{
Lucio Compagno, Diego D’Urso, and Natalia Trapani \\ Dipartimento di Ingegneria Industriale \\ Università degli Studi di Catania \\ \{lcompagno, ddurso, ntrapani\} @dii.unict.it
}

\begin{abstract}
The paper addresses the topic of designing the shape of a warehouse and shows a comparison between a standard storage-handling system, which is designed taking into account the minimization of the handling planar path, and the one which is designed trying to minimizing the overall handling energy consumption. This comparison leads to a discussion on the opportunities which result from the construction of a shallow warehouse in term of building construction costs, layout management and storage surface efficiency. This paper is the first step in the analysis of a more comprehensive research about the life cycle assessment of a warehouse, the manpower utilization and the balanced equilibrium between handling energy requirement and performances of most used handling systems.
\end{abstract}

Keywords: warehouse design, storage-handling system, sustainability.

\section{Introduction}

Contemporary literature reviews about research on warehouse design show that a perfect solution of the problem is yet missing [1].

A literature breakdown on warehouse design shows five main focus areas:

- conceptual design;

- $\quad$ sizing \& dimensioning;

- internal layout;

- equipment selection;

- operations management optimization.

Sizing \& dimensioning and internal layout are the most frequent research issues. Warehouse sizing defines the storage capacity and throughput requirements of a warehouse, while dimensioning translates the capacity requirements into a detailed floor space in order to assess construction and operating costs. Internal layout and equipment have to be assessed in order to achieve the best performances about:

- construction and maintenance costs;

- material handling costs;

- $\quad$ effective storage and throughput capacity;

- $\quad$ space and equipment utilization.

Usually the phases of a warehouse design are developed sequentially and entail an iterative analysis; this recursive procedure becomes as necessary as difficult if the 
contribution of operations management strategies to the warehouse capacities is to be considered (e.g. the class based storage strategy reduces storage requirement but increases the throughput time).

Relatively little has been written about the conceptual design; some authors try to define the high level warehouse structure as the type and number of areas (i.e. receiving, storing, order picking, shipping), the equipment and technologies that will be used and the operations strategies that would be implemented: usually the goal is to meet storage and throughput requirements minimizing only the overall discounted cost without an integrated life cycle analysis according to the sustainability methodology.

The state-of-the-art in warehouse designing entails a lot of simplifying hypotheses based on the uncertain knowledge about future operating conditions. On the other hand, there is a significant gap between the literature about warehouse design and operations research and practice, probably due to difficulty of dealing with complex systems design: a principle-based assessment of appropriate decision aiding for these high level design decisions is primarily requested [2], [3], [4, [5].

This paper evaluates the optimal shape of a warehouse and tries to suggest a different way to approach the conceptual design problem, based on the minimum action principle. This paper, principally, tries to move the attention on the human role and its "re-thinking" under a sustainable and not only economic plant scenario [6], [7].

\section{Methodology}

In order to evaluate the optimal warehouse shape a leading principle was chosen: the principle of minimum action. According to this law, everything happens in order to minimize some kind of mathematical functional. In designing an optimal shape warehouse, the material handling energy consumption was evaluated as such functional.

At this stage we considered only the energy consumption due to material-handling, neglecting the energy balance of the whole warehouse life cycle, as the energy sustainability assessment (e.g. the annual heat transfer, the initial construction energy, the energy requested by the end-of-life management).

Moreover, we didn't take in to account other environmental variables, for instance, the (agricultural) soil consumption.

We imposed also the following hypotheses [8], [9]:

h1. the warehouse geometry belongs to a continuous space;

h2. each point of the warehouse is visited with constant probability;

h3. the start/end point of material handling or picking is placed on a single point and it belongs to a vertex of the warehouse operative area (i/o in Figure 1);

h4. handling/picking requires single command cycles;

h5. the rolling friction coefficient is known and doesn't change with the mass of the unit load.

So the average expected path $(\mathrm{P})$ is (see Figure 1):

$$
P=H+W+D
$$

where $\mathrm{H}, \mathrm{W}$ and $\mathrm{D}$ are height, width and depth respectively of the operative warehouse volume. 

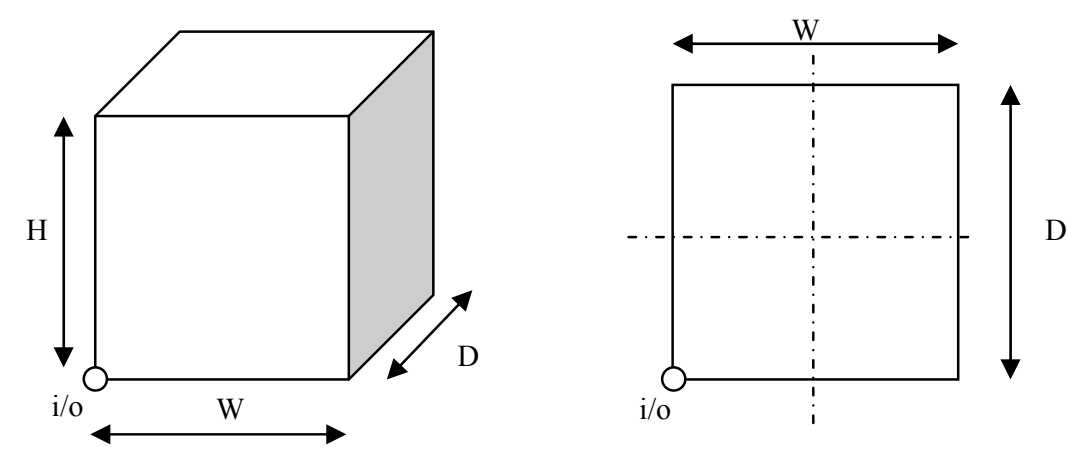

Fig. 1. The warehouse operating volume

The average expected energy consumption $(E C)$ can be written as a sum of horizontal and vertical contributions:

$E C=m g[H+r(W+D)]$

where, $r$ is the rolling friction coefficient.

It can be shown that the minimum expected path and energy consumption on the ground, according to hypothesis $h 3$, happens when:

$W=D$

So the equation (2) can be rewritten in the following form taking into account the constant value of the required warehouse volume $V_{R}$ :

$E C=m g\left(\frac{V_{R}}{W^{2}}+2 r W\right)$

The EC function of a single variable can be minimized according to the following differential process:

$\frac{d E C}{d W}=-2 \frac{V_{R}}{W^{3}}+2 r=0 \quad(5) ; W_{o p t}=\sqrt[3]{\frac{V_{R}}{r}}$

We can now arrange again equation (6) in order to derive the optimal warehouse shape: it has a square base and a height that depends on the rolling friction coefficient:

$W_{o p t} W_{o p t}^{2}=\frac{V_{R}}{r}$

where $V_{R}=H W D=H W^{2} W_{o p t}=\sqrt[3]{\frac{V_{R}}{r}} ; H_{o p t}=r W_{o p t} ; D_{o p t}=W_{o p t}$. 


\section{A Case Study}

The above mentioned procedure was applied in order to evaluate the optimal shape of a case study warehouse; we called it optimal shape warehouse (OSW); this optimal shape warehouse is then compared with a solution (SSW) - that we consider "standard"- of the same logistics problem considering the maximum number of warehouse levels $\left(\mathrm{NL}_{\mathrm{SSW}}\right)$ enabled by the building height.

With regard to the storage system, we assume the two warehouse scenarios are provided with a standard pallet racking solution; with regard to the handling system, we assume the SSW warehouse is also provided by an electric forklift (front loader) whereas the OSW one is provided by a hand pallet truck.

Table 1 shows the performances required to the handling-storage systems; packaging features are also showed.

Table 1. Case study designed performances and packaging features

\begin{tabular}{|c|c|c|c|}
\hline Variable & $\begin{array}{l}\text { Sym- } \\
\text { bol }\end{array}$ & $\begin{array}{l}\text { Val- } \\
\text { ue }\end{array}$ & $\begin{array}{ll} & \text { Unit } \\
\mathrm{s} & \\
\end{array}$ \\
\hline \multicolumn{4}{|c|}{ Designed warehouse performances } \\
\hline Designed storage capacity & DSC & 2.000 & $\mathrm{ul}$ \\
\hline Designed handling capacity & $\mathrm{DHC}$ & 30,0 & $\mathrm{ul} / \mathrm{h}$ \\
\hline \multicolumn{4}{|c|}{ Unit load measures } \\
\hline Average mass & $\mathrm{m}$ & 500,0 & $\mathrm{~kg}$ \\
\hline Width & $\mathrm{w}$ & 0,80 & $\mathrm{~m}$ \\
\hline Depth & $\mathrm{d}$ & 1,20 & $\mathrm{~m}$ \\
\hline Height & $\mathrm{h}$ & 0,15 & $\mathrm{~m}$ \\
\hline
\end{tabular}

Table 2 shows the measure of the unitary module measures of the storage system; those measures take into account the ergonomic handling distances between the unit load and the shelf or among one unit load and the others. To the unitary modules doesn't belong the pillars of the building.

Table 2. Unitary module features

\begin{tabular}{lllll}
\hline Unit module measures & Symbol & OSW & SSW & Units \\
\hline Width & UMW & 4,30 & 5,30 & $\mathrm{~m}$ \\
\hline Depth & UMD & 2,90 & 2,9 & $\mathrm{~m}$ \\
\hline Height & UMH & 1,65 & 1,65 & $\mathrm{~m}$ \\
\hline Aisle width & AW & 1,80 & 2,80 & $\mathrm{~m}$ \\
\hline Horizontal tolerance between unit loads & $\mathrm{a}$ & 0,10 & 0,10 & $\mathrm{~m}$ \\
\hline $\begin{array}{l}\text { Horizontal tolerance between unit load and the shelf pillar } \\
\text { centre }\end{array}$ & $\mathrm{b}$ & 0,15 & 0,15 & $\mathrm{~m}$ \\
\hline $\begin{array}{l}\text { Vertical tolerance between unit load and the shelf beam } \\
\text { centre }\end{array}$ & $\mathrm{c}$ & 0,15 & 0,15 & $\mathrm{~m}$ \\
\hline Horizontal tolerance between unit loads & $\mathrm{e}$ & 0,05 & 0,05 & $\mathrm{~m}$ \\
\hline Number of unit load per unitary module & $\mathrm{NUL}$ & 6,0 & 6,0 & - \\
\hline
\end{tabular}

Two different procedures were followed in order to design the optimal shape and the standard warehouse. Table 3 shows the main steps of calculations. 


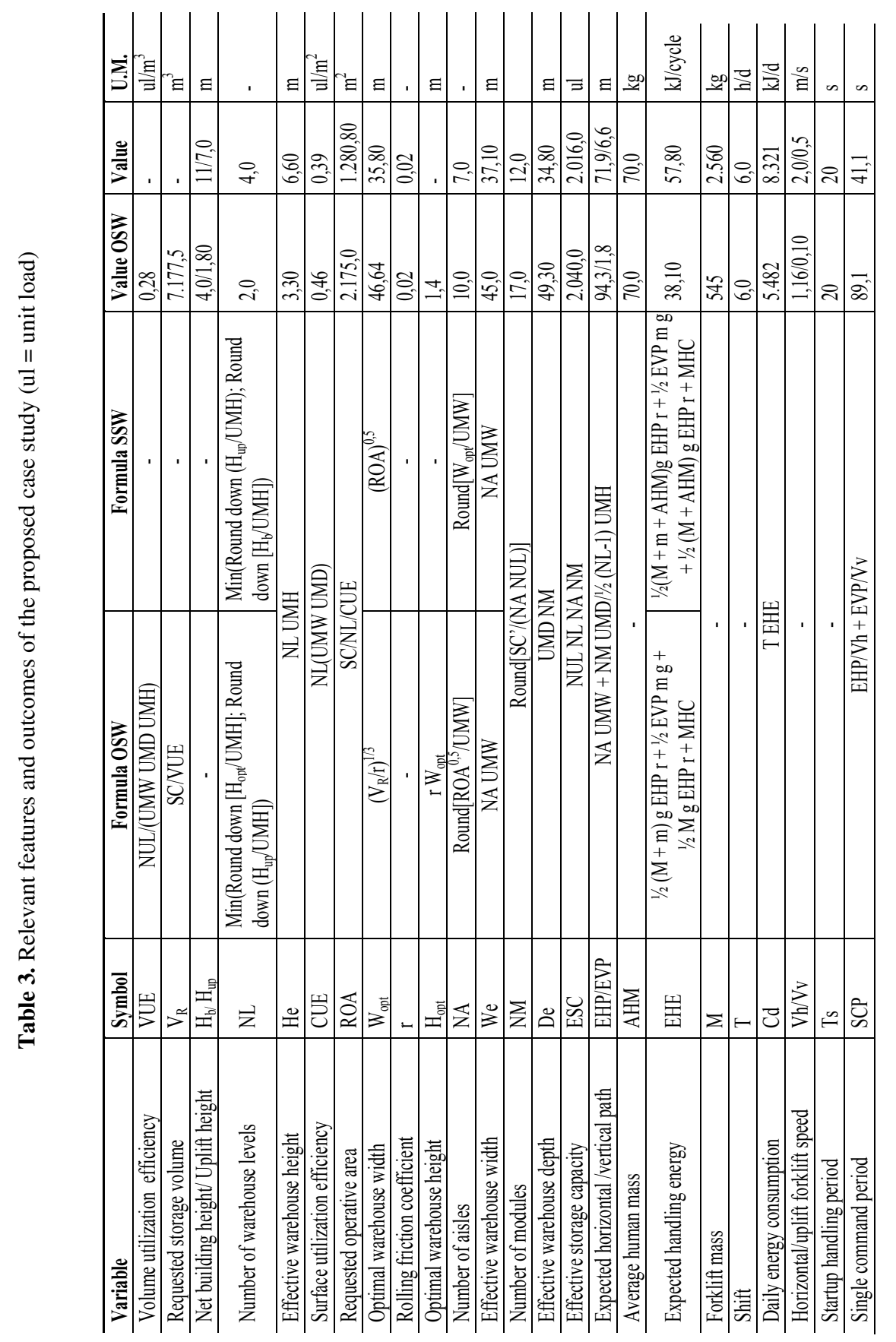




\section{$4 \quad$ Findings}

Table 4 shows a comparison among performances of the two above mentioned warehouses; both storage and handling systems fulfill the requested features and have comparable construction costs.

Table 4. OSW and SSW performances comparison

\begin{tabular}{|c|c|c|c|c|}
\hline \multirow[t]{2}{*}{ Description } & \multicolumn{2}{|c|}{ Value } & \multirow[t]{2}{*}{ Units } & \multirow[t]{2}{*}{$\Delta($ OSW-SSW $) / \mathrm{SSW}$} \\
\hline & OSW & SSW & & \\
\hline $\begin{array}{l}\text { Requested Storage capac- } \\
\text { ity }\end{array}$ & 2.000 & 2.000 & ul & - \\
\hline Effective Storage capacity & 2.040 & 2.016 & ul & $+1,19 \%$ \\
\hline $\begin{array}{l}\text { Requested handling capac- } \\
\text { ity }\end{array}$ & 24,0 & 24,0 & $\mathrm{~h}^{-1}$ & - \\
\hline $\begin{array}{l}\text { Effective handling capac- } \\
\text { ity }\end{array}$ & 33,2 & 59,1 & $\mathrm{~h}^{-1}$ & $-43,98 \%$ \\
\hline Daily energy consumption & $5.482,45$ & $8.321,38$ & $\mathrm{~kJ} / \mathrm{d}$ & $-34,12 \%$ \\
\hline $\begin{array}{l}\text { Requested operative vol- } \\
\text { ume }\end{array}$ & $7.321,1$ & $8.521,1$ & $\mathrm{~m}^{3}$ & $-14,08 \%$ \\
\hline Requested operative area & $2.175,00$ & $1.280,80$ & $\mathrm{~m}^{2}$ & $69,81 \%$ \\
\hline $\begin{array}{l}\text { Estimated cost of ware- } \\
\text { house construction }\end{array}$ & 150.000 & 140.000 & $€$ & $7,14 \%$ \\
\hline
\end{tabular}

In order to model the building construction cost $(\mathrm{Cc})$ an additive and parametric cost function was assumed, [10], [11]:

$$
\mathrm{C}_{\mathrm{c}}=\mathrm{C}_{\mathrm{s}}(\mathrm{S}, \mathrm{h})+\mathrm{C}_{\mathrm{f}}(\mathrm{S}, \mathrm{h})+\mathrm{C}_{\mathrm{p}}\left(\mathrm{S}^{\prime}, \mathrm{h}\right)+\mathrm{C}_{\mathrm{g}}(\mathrm{S}, \mathrm{h})
$$

where:

$\mathrm{C}_{\mathrm{s}}$ is the cost of elevated structure which can be considered as an assemble of precast concrete pillars and beams; $\mathrm{C}_{\mathrm{f}}$ is the cost of foundation; $\mathrm{C}_{\mathrm{p}}$ is the cost of side walls which are again constituted by precast concrete panels; $\mathrm{C}_{\mathrm{g}}$ is the cost of ground surface manufacturing.

The height of the building (h), the covered surface (S) and the building side surface (S') are the main cost drivers; Table 5 shows the analytic correlations which were taken in to account and how the scale factors influence the unitary cost evaluation; at the state of study the building height influences only the cost of the elevated structure; a further analysis is requested in order to better assess the cost reduction which a broader building entails in term of concrete foundation and ground surface arrangement.

At the state of study, material transportation and excavation costs were considered as not differential between the two scenarios. As regards to storage and handling systems we can again consider the procurement and assemble costs as no differential. 
Table 5. Drivers of main industrial building construction costs

\begin{tabular}{llllllll}
\hline Cost description & Symbol & Driver & SSW & OSW & Units & Equation & \\
\hline $\begin{array}{l}\text { building elevated } \\
\text { structure }\end{array}$ & $\mathrm{C}_{\mathrm{s}}$ & $\mathrm{S}, \mathrm{h}$ & 41,47 & 33,42 & $€ / \mathrm{m}^{2}$ & $\begin{array}{l}\mathrm{C}_{\mathrm{s}}=(-8,495 \\
98,2)(1+\mathrm{k}(\mathrm{h}))\end{array}$ & $\ln (\mathrm{S})+$ \\
\hline $\begin{array}{l}\text { building perimeter } \\
\text { walls }\end{array}$ & $\mathrm{C}_{\mathrm{p}}$ & $\mathrm{S}$, & 51,00 & 47,08 & $€ / \mathrm{m}^{2}$ & $\begin{array}{l}\mathrm{C}_{\mathrm{p}}=0,0014 \\
36,91\end{array}$ & $\mathrm{~S}+$ \\
\hline building foundation & $\mathrm{C}_{\mathrm{f}}$ & $\mathrm{S}, \mathrm{h}$ & 5,28 & 5,01 & $€ / \mathrm{m}^{2}$ & $\begin{array}{l}\mathrm{C}_{\mathrm{f}}=-0,568 \ln (\mathrm{S})+ \\
9,3438\end{array}$ & + \\
\hline $\begin{array}{l}\text { building ground } \\
\text { surface }\end{array}$ & $\mathrm{C}_{\mathrm{g}}$ & $\mathrm{S}, \mathrm{h}$ & 20,00 & 15,00 & $€ / \mathrm{m}^{2}$ & $\begin{array}{l}\mathrm{Cg}=-11,28 \\
102,28\end{array}$ & $\ln (\mathrm{S})+$ \\
\hline
\end{tabular}

The optimal shape warehouse (OSW), which is provided by a simpler material handling system, shows quite the same start up cost of the standard shape one (SSW) but enables a great reduction of the handling energy consumption.

The developed case study points out the following issues.

First of all, the optimal shape of a warehouse is broader than we would expect; that's because we take into account the energy consumption in a three dimensional handling problem with slip factors that change enormously moving from a horizontal path to a vertical one.

This broader geometric solution enables the manual material handling by using manual hand trucks.

Under the same boundary conditions, the requested manual material handling activity is comparable with the one of a slow walker (3,0 MET, Metabolic Equivalent of Task, [12]).

On the other side a broader warehouse can be structurally constituted by the same shelves which are used as a storage system; the focus can be now moved on the following opportunities:

1. a further cost reduction can be accomplished as a consequence of a more distributed mass load on foundation;

2. a more efficient surface utilization can be achieved if building pillar are inside the storage system;

3. a more sustainable building can be realised by using recycled material or innovative material with regard to the heat transfer;

4. a flexible layout management due to the disassembling capability allowed by this construction method.

Finally we want to point out another feature of the discussed optimal shape warehouse: the requested handling power is comparable with the power of the handling system implemented; the same requested handling power is comparable with the one provided by human activity; so a further analysis could verify if human material handling can be introduced, for example when a unit load has to be pushed during a horizontal path, in order to optimize the operations energy consumption. 


\section{Conclusions and Future Works}

The optimal warehouse shape is square base, according to the position of the single input/output point, and has a height that depends on the rolling friction coefficient. Due to the rolling friction coefficient value, $\mathrm{r} \simeq 0,02$, a minimum energy consumption warehouse should be shallow $(H=r W)$. A shallow warehouse enables the manual material handling and requires resources that belong to a natural life style (daily energy requirement), as shown in the above mentioned case study.

This study doesn't consider any discounted cash flow rate of return about the warehouse-plant but it wants to consider the warehouse design process from another points of view: the human, the natural and the sustainable one.

A further analysis is to be performed in order to quantify the contribution of energy and material balance during the phases of warehouse construction, operating life and end of life.

The above mentioned case study can be considered as a preliminary analysis of a whole life cycle assessment. The study points out on a better tradeoff between the effective handling-system energy requirement and the potential which is usually implemented.

\section{References}

1. Gu, J., Goetschalckx, M., McGinnis, L.F.: Research on warehouse design and performance evaluation: A comprehensive review. European Journal of Operational Research 203, 539549 (2010)

2. Baker, P., Canessa, M.: Warehouse design: A structured approach. European Journal of Operational Research 193, 425-436 (2009)

3. Ashayeri, J., Gelders, L.F.: Warehouse design optimization. European Journal of Operational Research 21, 285-294 (1985)

4. Apple, J.: Plant Layout and Material Handling, 3rd edn. John Wiley, New York (1977)

5. Rouwenhorst, B., Reuter, B., Stockrahm, V., Van Houtum, G.J., Mantel, R.J., Zijm, W.H.M.: Warehouse design and control: Framework and literature review. European Journal of Operational Research 122(3), 515-533 (2000)

6. Cormier, G., Kersey, D.F.: Conceptual design of a warehouse for just-in-time operations in a bakery. Computers and Industrial Engineering 29(1-4), 361 (1995)

7. Hung, M.S., Fisk, C.J.: Economic sizing of warehouses - A linear programming approach. Computers and Operations Research 11(1), 13-18 (1984)

8. Caron, F., Marchet, G., Perego, A.: Routing policies and COI-based storage policies in picker-to-part systems. International Journal of Production Research 36(3), 713-732 (1998)

9. Caron, F., Marchet, G., Perego, A.: Optimal layout in low-level picker-to-part systems. International Journal of Production Research 38(1), 101-117 (2000)

10. Cosenza, E., Fabbrocino, G., Iervolino, I., Lando, M.: Preventivazione sintetica del costo degli edifici industriali prefabbricati. Impiantistica Italiana, Anno XV (1), 43-50 (2002)

11. PCI Design Habdbook, Precast and Prestressed Concrete, 5th edn., PCI Institute, Chicago (1999)

12. Ainsworth, B.E., Haskell, W.L., Herrmann, S.D., Meckes, N., Bassett, D.R., Tudor-Locke, C., Greer, J.L., Vezina, J., et al.: 2011 Compendium of Physical Activities. Medicine \& Science in Sports \& Exercise 43(8), 1575-1581 (2011) 